\title{
A Brief Review on Dynamics of a Cracked Rotor
}

\author{
Chandan Kumar and Vikas Rastogi \\ Mechanical Engineering Department, Sant Longowal Institute of Engineering and Technology, Longowal, Punjab 148106, India \\ Correspondence should be addressed to Vikas Rastogi, rastogivikas@yahoo.com
}

Received 20 September 2009; Accepted 15 December 2009

Recommended by Koji Fujimoto

Fatigue crack is an important rotor fault, which can lead to catastrophic failure if undetected properly and in time. Study and Investigation of dynamics of cracked shafts are continuing since last four decades. Some review papers were also published during this period. The aim of this paper is to present a review on recent studies and investigations done on cracked rotor. It is not the intention of the authors to provide all literatures related with the cracked rotor. However, the main emphasis is to provide all the methodologies adopted by various researchers to investigate a cracked rotor. The paper incorporates a candid commentary on various methodologies. The paper further deals an extended Lagrangian formulation to investigate dynamics of cracked rotor.

Copyright ( 2009 C. Kumar and V. Rastogi. This is an open access article distributed under the Creative Commons Attribution License, which permits unrestricted use, distribution, and reproduction in any medium, provided the original work is properly cited.

\section{Introduction}

Fatigue cracks have great potential to cause catastrophic failures in rotating shaft. This fault may interrupt smooth, effective and efficient operation and performance of the machines. This problem has attracted the attention of researchers. Through various researches methodology investigation of dynamics of cracked rotor has been done, and work in this area is still continuing. Review papers are presented from time to time on this subject. The study and investigation in the last few decades on cracked rotors are presented in a review paper by Wauer [1]; Gasch [2] has presented a survey on simple rotor, Dimarogonas [3] has presented a review, and more recently presented by Sabnavis et al. [4]. Various methods like Wavelet transform, Finite element method, Nonlinear dynamics, Hilbert-Huang transform, and so forth, have been applied to study the dynamic behavior of a cracked rotor. Important achievements have been made during these years; the knowledge of the dynamical behavior of cracked shafts has helped in predicting presence of crack in a rotor. But there is demand for more powerful rotor nowadays. Hence more accurate and reliable technique is required to predict the generation and propagation of a crack in a rotating shaft. In this paper a candid comment on various approaches is presented. An alternate method based on extended Lagrangian mechanics to investigate the dynamics of cracked rotor will be discussed in brief.

\section{Different Modeling Approaches Applied to Investigate Cracked Rotor}

Study of cracked rotor is continuing since last four decades. Different modeling techniques are used by various researchers. These approaches can be presented in the next subsections.

2.1. HHT (Hilbert-Huang Transform). Guo and Peng [5] used Hilbert-Huang transform for detection and monitoring of crack in transient response of a cracked rotor. This method is particularly useful for identifying very small crack depths. Hilbert-Huang transform has good potential for nonlinear and nonstationary data analysis, especially for time-frequency-energy representations. Ramesh Babu et al. [6] have used HHT for detection of a crack. HHT appears to be a better tool compared to wavelet transform for crack detection.

2.2. Breathing Mechanism. Many researchers have analyzed the dynamics of cracked rotor by the approaches based on crack breathing. The crack gradually opens and closes during 
each revolution, in other words breaths during the revolution of the shaft; however, it is not yet entirely clear how partial closure interacts with key variables of the problem. Hence there is a need for a model that accounts for the crack breathing mechanism and for the interaction between external loading and dynamic crack behavior concluded by Bachschmid et al. [7]. The crack breathing in rotors is often simulated using two well-known models by Patel and Darpe [8]. One is the switching/hinge crack model, in which the stiffness of the rotor switches from one corresponding to the closed crack to the stiffness corresponding to the fully open crack state. The other model is the response dependent breathing crack model presented by Jun et al. [9].

2.3. Wavelet Transform and Wavelet Finite Element Approach. Wavelets method may be used to detect the damage location and depth by considering modal frequencies, modal shape, and modal damp, and so forth. Zheng et al. [10] applied the wavelet transform technique for bifurcation and chaos study. Wavelet transform can reveal the local property in both time domain and frequency domain. They introduced a method to analyze the existing domains of different types of motion in the parametric space of a nonlinear system. Yang et al. [11] have worked on characterization and detection of crackinduced rotary instability. They developed and presented a wavelet-based algorithm to characterize periodic, perioddoubling, fractural-like, and chaotic motions as results of the inherent nonlinearity associated with crack opening and closing during vibration. The most significant feature of this algorithm is that, it is capable of continuously identifying the transition state that marks the initiation and propagation of rotor dynamical mechanical stability. Darpe [12] has presented a method to detect transverse surface crack in a rotating shaft. His method was also based on wavelet transform techniques. Xiang et al. [13] have presented a wavelet finite element method for identification of crack in a rotor system and proposed a methodology to analyze the dynamic behavior of a Rayleigh beam.

Traditional FEM has some limitation, such as low efficiency, insufficient accuracy, slow convergence to correct solutions, and so forth, in case of complex problem with high gradient or strong nonlinearity. In order to overcome these difficulties, wavelet spaces have been employed as approximate spaces and then wavelet finite element methods (WFEM) have been derived by Ma et al. [14]. Chen et al. [15, 16] applied this technique to a dynamic multi scale lifting computation method using Daubechies wavelet. The desirable advantages of WFEM are multiresolution properties and various basis functions for structural analysis. Li et al. [17] proposed a methodology to detect crack location and size, which takes advantage of WFEM in the modal analysis for singularity problems like a cracked beam. By using WFEM model, Xiang et al. [18] gave the experimental identification results in cantilever beams with small identification errors. Xiang et al. [19] also proposed a BSWI Euler beam model for detecting crack in a beam, the simulation and experimental results show the high performance of the BSWI Euler beam element. The desirable advantages of WFEM are multiresolution properties and various basis functions for structural analysis.

2.4. Investigation through Finite Element Approach. Threedimensional (3D) FEA has attracted the researchers as an investigative tool for the study of crack breathing mechanism. Due to ease in simulation, many researchers applied finite element technique for analysis of crack in a rotating shaft. Papadopoulos and Dimarogonas [20] have analyzed for the local crack compliance for a six-degree-of-freedom crack beam segment. Alternatively the local compliance matrix can be determined through a 3D state finite element analysis by several researchers. Sekhar and Prabhu [21] have studied the vibration and stress fluctuation in cracked shafts and investigated a simply supported shaft with a transverse crack for the vibrational characteristics. Finite element analysis (FEA) has been carried out for free and force vibrations. Dirr et al. [22] worked for detection and simulation of small transverse cracks in rotating shafts. In their work, they developed a spatial finite element model and used it for numerical simulation of the dynamic behavior of a cracked rotor, in another study. Mohiuddin and Khulief [23] have investigated model characteristics of a cracked rotor using a conical shaft finite element and deduced frequency of the rotor in several cracked conditions. Sekhar and Balaji Prasad [24] worked on dynamic analysis of a rotor system considering a slant crack in shaft. FEM analysis of a rotor bearing system for flexural vibration has been considered in their work and they concluded a general trend of reduction in eigen frequencies of all models with an increase in crack depth. Sekhar [25] has investigated vibration characteristics of a cracked rotor with two opens and applied FEM analysis on rotor system for flexural vibration considering two transverse open crack. He concluded that in the case of two cracks of different depths, the larger crack has the more significant effect on the eigen frequency of the rotor. Nandi [26] has presented a simple method of reduction for finite element model of nonaxisymetric rotors on nonisotropic spring. Darpe [27] investigated the dynamics of a Jeffcott rotor with slant crack describing the flexibility matrix for the slant crack. Bachschmid and Tanzi [28] have looked at the straight front crack. Recently, Georgantzinos and Anifantis [29] studied the effect of the crack breathing mechanism on the time-variant flexibility due to the crack in a rotating shaft considering quasistatic approximation and using advanced nonlinear contact-FEM procedure. This method predicts the partial contact of crack surfaces, and it is appropriate to evaluate the instantaneous crack flexibilities.

Darpe et al. [30, 31] calculated the breathing by evaluating the rectilinear crack tip, the point where the crack is starting to close, assuming that the closed part of the crack surface is delimited by a boundary, the "crack closure line" (CCL) represented by a segment, orthogonal to the crack tip, that can be drawn from that point on the crack tip. The same approach has been used also by $\mathrm{Wu}$ et al. [32] in time step calculations where breathing was determined by vibrations. Unlike the previous studies, in Chasalevris and Papadopoulos [33] each crack is characterized by its depth, position, and relative angle. The compliance calculation 
method is applied for the first time in cracked shafts with rotated cracks. The compliance matrix of the crack in bending is calculated using the well-known method of integration of the strain energy density function over the opened crack surface.

2.5. Analysis through Nonlinear Dynamics of Cracked Rotor. Müller et al. [34] investigated nonlinear dynamics of a cracked rotating shaft using changing stiffness coefficient. Bovsunovskii [35] has done the numerical study of forced and decaying vibrations of a system simulating a body with a closing crack under the action of various modes of a nonlinear restoring force and linear viscous friction. In his study, he determined the natural frequency of transverse and longitudinal vibration of a cracked beam with an open and close crack.

Qin et al. [36] have investigated bifurcation in the response of cracked Jeffcott rotor. Nonlinear response of response of a cracked rotor due to bifurcation and its influence was illustrated in their study. Feng et al. [37] worked for nonlinear analysis of a cracked rotor with whirling. Distinct differences have been found in bifurcation, amplitude, orbit, and Poincare map when carrying on this comparison. The work may be useful in crack early detection and diagnosis. Zhu et al. [38] have investigated the dynamics of a cracked rotor with an active magnetic bearing, through their theoretical analysis they observed that it is impossible to use traditional method with super harmonic frequency components in the supercritical speed region to detect the crack. Zhou et al. [39] have analyzed the cracked rotor experimentally and investigated nonlinear dynamic characters of rotor system containing a transverse fatigue crack. Ishida and Inoue [40] have used piecewise model function and power series function for zetchin of a rotor crack by a harmonic excitation and nonlinear vibration analysis. Bachschmid et al. [41] evaluated all the nonlinear effects due to a rather deep transverse crack that has developed in a full size shaft. Time integration has been used for the nonlinear analysis of a heavy, horizontal axis, and well-damped steam turbine rotor. The results confirmed that neither instabilities nor subharmonic components did appear, and that the overall deviations from linear behavior were rather small.

2.6. Analysis of Crack Rotor through Several Other Techniques. Besides the above mentioned techniques, there are few techniques and methodologies developed by few researchers to analyze the dynamics of cracked rotor. Shulzhenko and Ovcharova [42] studied the effect of the break of the elastic axis of rotor with transverse crack on its vibrational characteristics and performed a numerical analysis to know the various effects on vibration due to the crack. Bachschmid et al. [43] have proposed a method for identification of the position and the depth of a transverse crack in a rotor system, by using vibration measurement technique. A model based diagnostic approach and a least squares identification method in the frequency domain are used for the crack localization along the rotor. Meng and Gasch [44] worked on stability and stability degree of a cracked flexible rotor supported on journal bearings and concluded that crack ridge zone depends largely on the speed ratio and the stiffness change ratio. Andrieux and Varé [45] worked on a 3D cracked beam model with unilateral contact, which may be applied on a rotor. They have given a general procedure for deriving a lumped cracked section beam model, which has been designed with 3D computations and incorporating more realistic behavior of the crack, under variable loading. Sekhar [46] has proposed a model-based approach for cracked identification in a rotor system with a suggestion that the better expansion techniques or refined modal expansion method should be incorporated to get better results and to finally get this scheme. Sekhar et al. [47] have investigated the dynamics of the rotor system with two slant cracks and a transverse crack and found that the effect of transverse crack is highly sensitive to mechanical impedance compared to slant crack. Gómez-Mancilla et al. [48] have investigated the influence of transverse crack in a rotating shaft and noted that as the crack depth increase, an increase of the orbit completed is observed in the rotor. Huang and Liu [49] have presented a dynamic analysis of rotating beams with nonuniform cross sections using the dynamic stiffness method. They, however, used Hamilton's principle for the numerical analysis and prepared dynamic stiffness matrix for numerical analysis.

2.7. Recent Developments in Cracked Rotor Analysis. Since the last two years, few papers have appeared in various archives, where few new methods and tools have been applied for analysis of dynamics of rotor and its correct prediction. Chang et al. [50] have studied nonlinear response and dynamic stability of a cracked rotor. They developed nonlinear governing equations of motion for the cracked rotor system with asymmetrical visco elastic supports. Mueller et al. [51] have presented a comparison of different approaches for estimation of a creep crack initiation and compared the time dependent failure assessment diagram (TDFAD), two criteria diagram (ZCD), and Nikbin-Smith Webster model (NSWmodel) approaches for predicting creep crack initiation. It has been found that TDFAD and NSW-model method are costly but ZCD is a simple method. In another recent literature, Dong et al. [52] introduced a novel crack detection method based on high precision modal parameter identification in the BSWI finite element framework, where Empirical mode decomposition and Laplace wavelet are proposed. From the selected, ten largest correlation coefficients and the corresponding parameters of natural frequency and damping are identified. The errors in the WFE model are minimized by finite element model updating technique, such as output error method is for this application. The effectiveness of the proposed method is verified by an experiment and crack parameters are identified. A comprehensive theoretical, numerical, and experimented approach for crack detection in power plant rotating machinery has been presented by Stoisser and Audebert [53]. In this study, they developed a 3D theoretical cracked beam model and presented a numerical simulation, which has been validated through experimental results. In a recent study Jun and Gadala [54] investigated the dynamic behavior analysis of cracked rotor, 
by considering an additional slope in the crack breathing. In this analysis fracture mechanics concept was used and response of cracked rotor was formulated based on transfer matrix method. Recently, Xiang et al. [55] constructed BSWI rotating Rayleigh-Euler and Rayleigh-Timoshenko beam elements to obtain a precision crack detection database, whereas the inverse problem of normalized crack location and depth is detected using genetic algorithm. Pennacchi and Vania [56] have analyzed the shaft vibrations of a $100 \mathrm{MW}$ power unit. The results obtained with a model-based analysis of the shaft vibrations caused by the propagation of a crack occurred in the load coupling connected to the gas turbine of a power unit are discussed.

\section{Alternative Proposal for Cracked Rotor through Extended Lagrangian Mechanics}

Among the various analytical techniques used by various researchers, Lagrangian mechanics are one of the area, where few works have been reported in literature. It is a well-known phenomenon that asymmetric rotating component produces nonpotential and dissipative forces, and classical Lagrange's equation cannot analyze the dynamics of such system with nonholonomic constraints, nonpotential forces, dissipative forces, gyroscopic forces, and general class of systems with time fluctuating parameters, as such Lagrangian cannot be worked out due to nonconservative forces involved in the system. So some additional information of system interior and exterior is needed in generating extended Lagrangian equations through bond graphs [57-59], which may be applicable to the crack rotor system. The symmetries of the system also provide useful information to derive the constant of motion of the system as they reduce the complexity of the dynamical systems such as cracked rotor. Noether's theorem [60] played a significant role in determination of invariants of motion. Noether's theorem allows exploitation of symmetries of the system to arrive at invariant of motion. Extended Noether's theorem with Umbra's Hamiltonian provides the insight of dynamics of the asymmetric rotor system.

To enlarge the scope of Lagrangian-Hamiltonian mechanics, a new proposal of additional time like variable "umbratime" was made by Mukherjee [61] and this new concept of umbra-time leads to a peculiar form of equation, which is termed as umbra-Lagrange's equation. A brief and candid commentary on the idea of umbra Lagrangian is given by Brown [62]. This idea was further consolidated by presenting an important issue of invariants of motion for the general class of system by extending Noether's theorem [63]. This notion of Umbra-time is again used to propose a new concept of umbra-Hamiltonian, which is used along with the extended Noether's theorem to provide an insight into the dynamics of systems with symmetries. One of the most important insights gained from the umbra-Lagrangian formalism is that its underlying variational principle [64] is possible, which is based on their cursive minimization of functionals. Once such a least action principle is established, many significant results of analytical mechanics may be extended to a general class of system. In this direction [64] defined all these notions in an extended manifold comprising of real time, and umbra and real time displacements and velocities. The umbra-Lagrangian theory has been used successfully to study invariants of motion for nonconservative mechanical and thermomechanical systems [65]. Recently Mukherjee et al. [66] applied umbra Lagrangian to study dynamics of an electromechanical system comprising of an induction motor driving an elastic rotor. In another research work, the same authors [67] have provided the dynamics a one-dimensional internally damped rotor through dissipative coupling. Moreover Rastogi and Kumar [68] investigated the dynamic behavior of asymmetric rotor by extending the Lagrangian-Hamiltonian Mechanics. This is in line to broaden the scope of umbra-Lagrangian formulation applied to this rotor dynamic research. In this paper, symmetry of the rotor is broken in terms of stiffness only and it may be applied in other cases also.

\section{Conclusions}

After an exhaustive survey of literature, the potential researchers in this field have various tools and methodologies to be applied to detect and proper identification of a crack. The methodologies have some specific advantages over the other. Now, there is a choice before the dynamics people to adopt proper techniques. The paper may be concluded as follows.

(i) Crack breathing mechanism plays an important role in analysis of dynamic behavior of a cracked rotor. This breathing phenomena must be modeled accurately to detect the crack in a rotor.

(ii) Wavelet transform method was used by various researchers to predict the generation and propagation of a crack in rotating shaft. This propagation mechanism may be modeled so that the early failure of the rotor shaft may be detected.

(iii) Finite element method is a better choice and applied by various researchers to analyze the dynamic behavior of a shaft having different kind of cracks, for example, transverse crack, two cracks, slant crack, and so forth. The crack element must be accurately discretized to depict the real behavior of a cracked rotor.

(iv) Wavelet along with finite element method is also a good choice to have advantages of both techniques. Recently wavelet along with genetic algorithm analysis is also finding place in the various Literature.

(v) The proposal of extended lagrangian-Hamiltonian formulation provides the invariants of motion of the dynamical system. It provides a great insight of the dynamics of a cracked rotor through extended Noether's theorem. 


\section{References}

[1] J. Wauer, "On the dynamics of cracked rotors: a literature survey," Applied Mechanics Reviews, vol. 43, pp. 13-17, 1990.

[2] R. Gasch, "A survey of the dynamic behavior of a simple rotating shaft with a transverse crack," Journal of Sound and Vibration, vol. 160, no. 2, pp. 313-332, 1983.

[3] A. D. Dimarogonas, "Vibration of cracked structure: a state of the art review," Engineering Fracture Mechanics, vol. 55, no. 5, pp. 831-857, 1996.

[4] G. Sabnavis, R. G. Kirk, M. Kasarda, and D. Quinn, "Cracked shaft detection and diagnostics: a literature review," Shock and Vibration Digest, vol. 36, no. 4, pp. 287-296, 2004.

[5] D. Guo and Z. K. Peng, "Vibration analysis of a cracked rotor using Hilbert-Huang transform," Mechanical Systems and Signal Processing, vol. 21, no. 8, pp. 3030-3041, 2007.

[6] T. Ramesh Babu, S. Srikanth, and A. S. Sekhar, "HilbertHuang transform for detection and monitoring of crack in a transient rotor," Mechanical Systems and Signal Processing, vol. 22, no. 4, pp. 905-914, 2008.

[7] N. Bachschmid, P. Pennacchi, and E. Tanzi, "Some remarks on breathing mechanism, on non-linear effects and on slant and helicoidal cracks," Mechanical Systems and Signal Processing, vol. 22, no. 4, pp. 879-904, 2008.

[8] T. H. Patel and A. K. Darpe, "Influence of crack breathing model on nonlinear dynamics of a cracked rotor," Journal of Sound and Vibration, vol. 311, no. 3-5, pp. 953-972, 2008.

[9] O. S. Jun, H. J. Eun, Y. Y. Earmme, and C.-W. Lee, "Modelling and vibration analysis of a simple rotor with a breathing crack," Journal of Sound and Vibration, vol. 155, no. 2, pp. 273290, 1992.

[10] L. Zheng, H. Gao, and T. Guo, "Application of wavelet transform to bifurcation and chaos study," Applied Mathematics and Mechanics, vol. 19, no. 6, pp. 593-599, 1998.

[11] B. Yang, C. S. Suh, and A. K. Chan, "Characterization and detection of crack-induced rotary instability," Journal of Vibration and Acoustics, vol. 124, no. 1, pp. 40-48, 2002.

[12] A. K. Darpe, "A novel way to detect transverse surface crack in a rotating shaft," Journal of Sound and Vibration, vol. 305, no. 1-2, pp. 151-171, 2007.

[13] J. W. Xiang, X. F. Chen, Q. Mo, and Z. J. He, "Identification of crack in a rotor system based on wavelet finite element method," Finite Elements in Analysis and Design, vol. 43, no. 14, pp. 1068-1081, 2007.

[14] J. X. Ma, J. J. Xue, S. J. Yang, and Z. J. He, "A study of the construction and application of a Daubechies wavelet-based beam element," Finite Elements in Analysis and Design, vol. 39, no. 10, pp. 965-975, 2003.

[15] X. F. Chen, S. J. Yang, J. X. Ma, and Z. J. He, "The construction of wavelet finite element and its applications," Finite Elements in Analysis and Design, vol. 40, no. 5-6, pp. 541-554, 2004.

[16] X. F. Chen, Z. J. He, J. W. Xiang, and B. Li, "A dynamic multiscale lifting computation method using Daubechies wavelet," Journal of Computational and Applied Mathematics, vol. 188, no. 2, pp. 228-245, 2006.

[17] B. Li, X. F. Chen, J. X. Ma, and Z. J. He, "Detection of crack location and size in structures using wavelet finite element methods," Journal of Sound and Vibration, vol. 285, no. 4-5, pp. 767-782, 2005.

[18] J. W. Xiang, X. F. Chen, B. Li, Y. M. He, and Z. J. He, "Identification of a crack in a beam based on the finite element method of a B-spline wavelet on the interval," Journal of Sound and Vibration, vol. 296, no. 4-5, pp. 1046-1052, 2006.
[19] J. W. Xiang, X. F. Chen, Q. Mo, and Z. J. He, "Identification of crack in a rotor system based on wavelet finite element method," Finite Elements in Analysis and Design, vol. 43, no. 14, pp. 1068-1081, 2007.

[20] C. A. Papadopoulos and A. D. Dimarogonas, "Coupling of bending and torsional vibration of a cracked Timoshenko shaft," Ingenieur-Archiv, vol. 57, no. 4, pp. 257-266, 1987.

[21] A. S. Sekhar and B. S. Prabhu, "Vibration and stress fluctuation in cracked shafts," Journal of Sound and Vibration, vol. 169, no. 5, pp. 655-667, 1994.

[22] B. O. Dirr, K. Popp, and W. Rothkegel, "Detection and simulation of small trasverse cracks in rotating shafts," Archive of Applied Mechanics, vol. 64, no. 3, pp. 206-222, 1994.

[23] M. A. Mohiuddin and Y. A. Khulief, "Modal characteristics of cracked rotors using a conical shaft finite element," Computer Methods in Applied Mechanics and Engineering, vol. 162, no. 1-4, pp. 223-247, 1998.

[24] A. S. Sekhar and P. Balaji Prasad, "Dynamic analysis of a rotor system considering a slant crack in the shaft," Journal of Sound and Vibration, vol. 208, no. 3, pp. 457-473, 1997.

[25] A. S. Sekhar, "Vibration characteristics of a cracked rotor with two open cracks," Journal of Sound and Vibration, vol. 223, no. 4, pp. 497-512, 1999.

[26] A. Nandi, "Reduction of finite element equations for a rotor model on non-isotropic spring support in a rotating frame," Finite Elements in Analysis and Design, vol. 40, no. 9-10, pp. 935-952, 2004.

[27] A. K. Darpe, "Dynamics of a Jeffcott rotor with slant crack," Journal of Sound and Vibration, vol. 303, no. 1-2, pp. 1-28, 2007.

[28] N. Bachschmid and E. Tanzi, "Deflections and strains in cracked shafts due to rotating loads: a numerical and experimental analysis," International Journal of Rotating Machinery, vol. 10, pp. 283-291, 2004.

[29] S. K. Georgantzinos and N. K. Anifantis, "An insight into the breathing mechanism of a crack in a rotating shaft," Journal of Sound and Vibration, vol. 318, no. 1-2, pp. 279-295, 2008.

[30] A. K. Darpe, K. Gupta, and A. Chawla, "Dynamics of a bowed rotor with a transverse surface crack," Journal of Sound and Vibration, vol. 296, no. 4-5, pp. 888-907, 2006.

[31] A. K. Darpe, "Coupled vibrations of a rotor with slant crack," Journal of Sound and Vibration, vol. 305, no. 1-2, pp. 172-193, 2007.

[32] X. Wu, M. I. Friswell, J. T. Sawicki, and G. Y. Baaklini, "Finite element analysis of coupled lateral and torsional vibrations of a rotor with multiple cracks," in Proceedings of the ASME Turbo Expo 2005: Gas Turbine Technology: Focus for the Future, vol. 4, pp. 841-850, Reno, Nev, USA, June 2005.

[33] A. C. Chasalevris and C. A. Papadopoulos, "Identification of multiple cracks in beams under bending," Mechanical Systems and Signal Processing, vol. 20, no. 7, pp. 1631-1673, 2006.

[34] P. C. Müller, J. Bajkowski, and D. Söffker, "Chaotic motions and fault detection in a cracked rotor," Nonlinear Dynamics, vol. 5, no. 2, pp. 233-254, 1994.

[35] A. P. Bovsunovskii, "On determination of the natural frequency of transverse and longitudinal vibrations of a cracked beam," Strength of Materials, vol. 31, no. 2, pp. 130-137, 1999.

[36] W. Qin, G. Chen, and X. Ren, "Grazing bifurcation in the response of cracked Jeffcott rotor," Nonlinear Dynamics, vol. 35, no. 2, pp. 147-157, 2004.

[37] L. X. Feng, X. U. Ping-Youn, S. Lin, and S. Yang, "Non linear analysis of a cracked rotor with whirling," Applied Mathematics and Mechanics, vol. 23, pp. 721-731, 2002. 
[38] C. Zhu, D. A. Robb, and D. J. Ewins, "The dynamics of a cracked rotor with an active magnetic bearing," Journal of Sound and Vibration, vol. 265, no. 3, pp. 469-487, 2003.

[39] T. Zhou, Z. Sun, J. Xu, and W. Han, "Experimental analysis of cracked rotor," Journal of Dynamic Systems, Measurement and Control, vol. 127, no. 3, pp. 313-320, 2005.

[40] Y. Ishida and T. Inoue, "Detection of a rotor crack using a harmonic excitation and nonlinear vibration analysis," Journal of Vibration and Acoustics, vol. 128, no. 6, pp. 741-749, 2006.

[41] N. Bachschmid, P. Pennacchi, and E. Tanzi, "Some remarks on breathing mechanism, on non-linear effects and on slant and helicoidal cracks," Mechanical Systems and Signal Processing, vol. 22, no. 4, pp. 879-904, 2008.

[42] N. G. Shulzhenko and G. B. Ovcharova, "Effect of break of the elastic axis of a rotor with transverse crack on its vibrational characteristics," Strength of Material, vol. 29, no. 4, pp. 380385, 1997.

[43] N. Bachschamid, P. Pennacchie, E. Tanzi, and Avana, "Identification of transverse crack position and depth in motor system," Meccanica, vol. 35, pp. 563-582, 2000.

[44] G. Meng and R. Gasch, "Stability and stability degree of a cracked flexible rotor supported on journal bearings," Journal of Vibration and Acoustics, vol. 122, no. 2, pp. 116-125, 2000.

[45] S. Andrieux and C. Varé, "A 3D cracked beam model with unilateral contact. Application to rotors," European Journal of Mechanics, A/Solids, vol. 21, no. 5, pp. 793-810, 2002.

[46] A. S. Sekhar, "Crack identification in a rotor system: a modelbased approach," Journal of Sound and Vibration, vol. 270, no. 4-5, pp. 887-902, 2004.

[47] A. S. Sekhar, A. R. Mohanty, and S. Prabhakar, "Vibrations of cracked rotor system: transverse crack versus slant crack," Journal of Sound and Vibration, vol. 279, no. 3-5, pp. 12031217, 2005.

[48] J. Gómez-Mancilla, J.-J. Sinou, V. R. Nosov, F. Thouverez, and A. Zambrano, "The influence of crack-imbalance orientation and orbital evolution for an extended cracked Jeffcott rotor," Comptes Rendus Mecanique, vol. 332, no. 12, pp. 955-962, 2004.

[49] K. J. Huang and T. S. Liu, "Dynamic analysis of rotating beams with nonuniform cross sections using the dynamic stiffness method," Journal of Vibration and Acoustics, vol. 123, no. 4, pp. 536-539, 2001.

[50] P. C. Chang, D. Liming, and F. Yiming, "Non linear response and dynamic stability of a cracked rotor," Communications in Nonlinear Science and Numerical Simulation, vol. 12, pp. 10231037, 2007.

[51] F. Mueller, A. Scholz, and C. Berger, "Comparison of different approaches for estimation of creep crack initiation," Engineering Failure Analysis, vol. 14, no. 8, pp. 1574-1585, 2007.

[52] H. B. Dong, X. F. Chen, B. Li, K. Y. Qi, and Z. J. He, "Rotor crack detection based on high-precision modal parameter identification method and wavelet finite element model," Mechanical Systems and Signal Processing, vol. 23, no. 3, pp. 869-883, 2009.

[53] C. M. Stoisser and S. Audebert, "A comprehensive theoretical, numerical and experimental approach for crack detection in power plant rotating machinery," Mechanical Systems and Signal Processing, vol. 22, pp. 818-844, 2008.

[54] O. S. Jun and M. S. Gadala, "Dynamic behavior analysis of cracked rotor," Journal of Sound and Vibration, vol. 309, no. 1-2, pp. 210-245, 2008.
[55] J. W. Xiang, Y. Zhong, X. F. Chen, and Z. J. He, "Crack detection in a shaft by combination of wavelet-based elements and genetic algorithm," International Journal of Solids and Structures, vol. 45, no. 17, pp. 4782-4795, 2008.

[56] P. Pennacchi and A. Vania, "Diagnostics of a crack in a load coupling of a gas turbine using the machine model and the analysis of the shaft vibrations," Mechanical Systems and Signal Processing, vol. 22, no. 5, pp. 1157-1178, 2008.

[57] D. C. Karnopp, R. C. Rosenberg, and D. L. Margolis, System Dynamics: A Unified Approach, John Wiley \& Sons, New York, NY, USA, 1990.

[58] P. C. Breedveld and G. Dauphin-Tanguy, Bond Graphs for Engineers, North-Holland, Amsterdam, The Netherlands, 1992.

[59] P. Gawthrop and L. Smith, MetaModeling: Bond Graphs and Dynamic Systems, Prentice-Hall, Upper Saddle River, NJ, USA, 1996.

[60] E. Noether, "Invariant variationsprobleme," Ges. Wiss. Worthington, vol. 2, pp. 235-257, 1918.

[61] A. Mukherjee, "Junction structures of bondgraph theory from analytical mechanics viewpoint," in Proceedings of the 1st Joint Conference of International Simulation Societies (CISS '94), pp. 661-666, Zurich, Switzerland, 1994.

[62] F. T. Brown, Engineering System Dynamics, CRC, Taylor and Francis, London, UK, 2nd edition, 2007.

[63] A. Mukherjee, "The issue of invariants of motion for general class of symmetric systems through bond graph and umbraLagrangian," in Proceedings of the International Conference on Bond Graph Modeling and Simulation (ICBGM '01), p. 295, Phoenix, Ariz, USA, 2001.

[64] V. Rastogi, Extension of Lagrangian-Hamiltonian mechanics, study of symmetries and invariants, Ph.D. thesis, Indian Institute of Technology, Kharagpur, India, 2005.

[65] A. Mukherjee, V. Rastogi, and A. Dasgupta, "A methodology for finding invariants of motion for asymmetric systems with gauge-transformed umbra Lagrangian generated by bond graphs," Simulation, vol. 82, no. 4, pp. 207-226, 2006.

[66] A. Mukherjee, V. Rastogi, and A. Dasgupta, "A study of a Bi-symmetric electro-mechanical system through UmbraLagrangian generated by bondgraphs, and Noether's theorem," Simulation, vol. 83, no. 9, pp. 611-630, 2007.

[67] A. Mukherjee, V. Rastogi, and A. Dasgupta, "Extension of Lagrangian-Hamiltonian mechanics for continuous systemsinvestigation of dynamics of a one-dimensional internally damped rotor driven through a dissipative coupling," Nonlinear Dynamics, vol. 58, no. 1-2, pp. 107-127, 2009.

[68] V. Rastogi and C. Kumar, "Investigation of dynamics of asymmetric rotor through Lagrangian formalism," in Proceedings of the IUTAM Symposium on Emerging Trends in Rotor Dynamics (IUROTOR '09), IIT Delhi, Delhi, India, March 2009. 

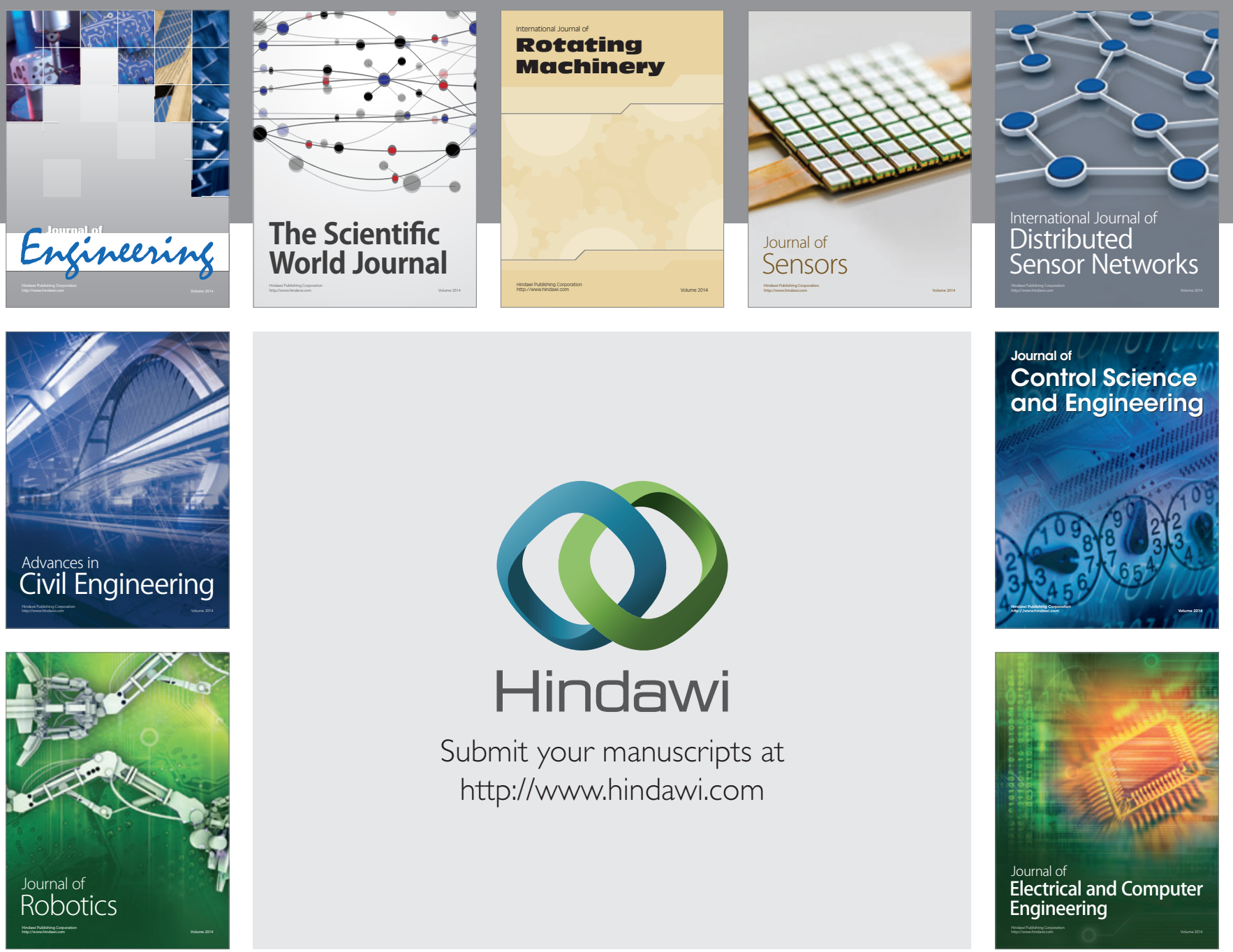

Submit your manuscripts at

http://www.hindawi.com
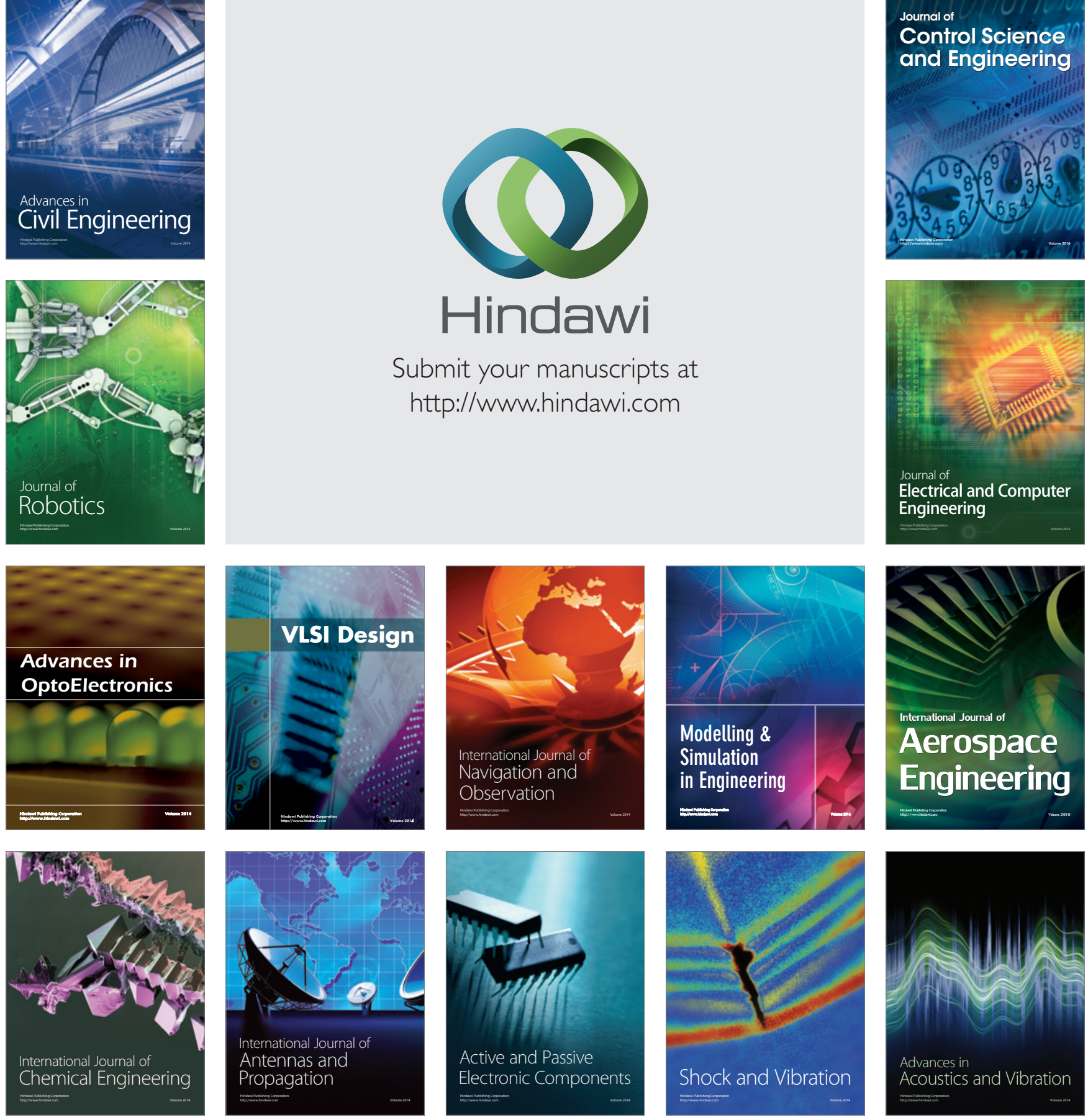